\title{
Perancangan dan Realisasi Kontrol Prototype Landing Gear System Menggunakan PLCmikro berbasis Mikrokontroller PI C16F877A
}

\author{
RATNA SUSANA ${ }^{1}$, USEP ALI ALBAYUMI ${ }^{2}$, NI CKY I LHAM TRI ADHY ${ }^{1}$ \\ 1. Teknik Elektro Institut Teknologi Nasional (ITENAS) Bandung \\ 2. PT. Dirgantara Indonesia \\ Email : ratnassn@yahoo.com
}

\begin{abstract}
ABSTRAK
Landing gear system merupakan suatu sistem penggerak pada roda pesawat yang menggunakan electromechanic system dengan sejumlah relay tanpa control terpusat. Melalui penelitian ini, electromechanic system tersebut diubah menjadi landing gear system yang dikendalikan secara terpusat menggunakan mikrokontroller dan diprogram oleh Idmikro berbahasa ladder diagram yang kemudian lebih dikenal dengan nama "PLCmikro". Input discreate digunakan untuk menggerakkan aktuator solenoid valve agar piston double acting cylinder dapat bekerja sesuai sistem yang diinginkan. Input analog digunakan sebagai informasi ketinggian pesawat minimum agar pesawat tetap aman terbang di udara. Control Landing gear system yang direalisasikan berhasil menggerakkan piston masuk maupun keluar dari tabung, memberikan informasi proses pergerakkan piston yang bermasalah dan posisi roda yang telah masuk atau keluar dari pesawat berupa lampu LED. Sistem ini juga berhasil membaca informasi ketinggian minimum pesawat dari potensiometer serta mengubahnya menjadi informasi suara dan lampu LED.
\end{abstract}

Kata kunci: Landing gear system, PLCmikro, Ldmikro, ladder diagram, double acting cylinder.

\begin{abstract}
The landing gear system an aircraft wheel drive system that uses electromechanic system with a relay without any centralized control. Through this study, the electromechanic system was changed to landing gear system with a centrally controlled by using microcontroller and programmed with Idmikro ladder diagram language which came to be known by the name of "PLCmikro". Discreate input used to drive the actuator solenoid valve double acting cylinder so that the piston can work as desired system. The analog input is used as the minimum flight altitude information to keep the plane safe to fly in the air. Landing gear control system is realized successfully drive the piston in and out of the tube, providing information processes are problematic piston movement and wheel position that has entered or exited the plane in the form of LED lights. The system also successfully read the minimum altitude aircraft information of the potentiometer and turn it into information sounds and LED lights.
\end{abstract}

Keywords: Landing gear system, PLCmikro, Ldmikro, ladder diagram, double acting cylinder. 


\section{PENDAHULUAN}

Landing gear system merupakan sistem gerak roda pesawat ketika pendaratan (landing) maupun penerbangan (take off). Pada pesawat terbang, umumnya sistem kontrol yang digunakan dalam landing gear system yang sebenarnya adalah menggunakan electromechanic system berupa susunan rangkaian relay. Electromechanic system merupakan sistem yang menggunakan rangkaian relay dari setiap inputnya tanpa control terpusat. Penelitian ini bertujuan untuk melakukan kontrol terhadap prototipe landing gear system menggunakan PLCmikro dan diprogram oleh Ldmikro berbahasa ladder diagram.

Spesifikasi yang dibutuhkan untuk landing gear system yaitu;

1. Sensor proximity wheight on wheel (WOW)

2. Sensor ketinggian menggunakan radio altimeter

3. Ground locking pin dan uplock pin berupa limit switch

4. Handle gear up dan gear down

5. Aktuator berupa solenoid valve $4 / 3$

6. Main landing gear actuator (MLG) berupa silinder aksi ganda (double acting cylinder).

7. Pintu utama roda (Main landing gear door)

8. Main beam

9. Lampu indikator hijau untuk indikasi roda pesawat telah keluar sempurna

10. Lampu indikator putih untuk indikasi roda pesawat telah masuk sempurna ke dalam pesawat

11. Lampu indikator kuning untuk indikasi roda pesawat sedang berproses masuk atau keluar.

12. Lampu indikator biru untuk indikasi warning jamming yang bermasalah pada proses MLG.

13. Lampu indikator merah untuk indikasi ketinggian pesawat yang melewati batas minimumnya.

14. Alarm juga sebagai indikasi untuk ketinggian pesawat yang melewati batas minimumnya.

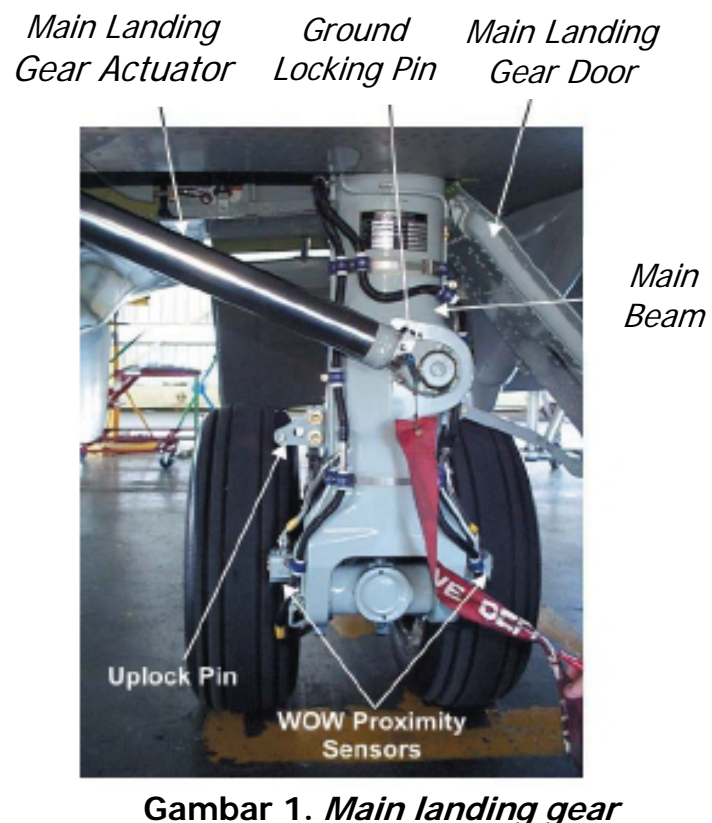


Menurut Eka (Eka P.H., 1983), dalam penelitiannya yang berjudul Rancangan Aktuator Pada Roda Pendarat Depan Pesawat N-228, menjelaskan bahwa roda pendarat depan dan utama dapat dimasukkan dan dikeluarkan secara serentak dengan tenaga hidraulis. Roda pendarat depan pada dasarnya terdiri atas kaki roda pendarat, aktuator penggerak, peralatan penguncian dan peralatan indikator keadaan roda pada posisi extend atau retract. Pengoperasian hidrolis dilakukan oleh aktuator aksi ganda yang terdiri atas silinder yang terpasang pada struktur pesawat dan tangki aktuator pada kaki roda pendarat. Aktuator ini bekerja dengan supply hidrolis untuk menarik dan mengeluarkan roda pendarat.

Penelitian Emil (Emil Bambang S, 1991) dalam perencanaan awal roda pendarat sistem twin wheel pada pesawat $\mathrm{CN}-235$ menjelaskan bahwa roda pendarat $\mathrm{CN}-235$ adalah model tricycle retractable dimana roda pendarat utama melipat ke belakang dan roda pendarat depan melipat ke depan. Retracting dan extending pada roda pendarat utama dan depan dilakukan secara hidraulik dan dikontrol secara electromechanic. Pada keadaan darurat akibat kegagalan sistem hidraulik, dengan pengaruh gravitasi, roda pendarat depan dan utama dapat diturunkan dengan cara membuang fluida pada aktuator dan menarik handle sehingga alat pengunci atas terlepas dan roda pendarat dapat turun.

Penelititan yang dilakukan Donny (Donny Wierya P., 2012) dalam jurnal tugas akhirnya mengenai rancang bangun prototipe robot pengangkut pallet dengan teknik kontrol wireless berbasis PLCmikro telah berhasil membuat suatu robot pengangkat pallet yang efisien dengan menggunakan wireless berbasis PLCmikro sebagai pengendalinya untuk dipakai di dunia industri. Robot ini dapat mengangkut pallet yang telah berisikan suatu beban kemudian menggunakan wireless yang terkoneksi pada PLCmikro sebagai pengendalinya.

Berdasarkan beberapa kajian pustaka yang telah penulis lakukan, maka pada penelitian ini landing gear system yang semula menggunakan electromechanic system berupa relay-relay diubah dan direalisasikan menjadi landing gear system yang dikendalikan secara terpusat menggunakan mikrokontroller. Mikrokontroller yang digunakan telah diprogram menggunakan bahasa ladder diagram yang selanjutnya dikenal dengan nama "PLCmikro". Penelitian ini membahas bagaimana PLCmikro dapat mengatur kerja landing gear system, mulai pada saat pesawat di landasan, saat lepas landas, saat di udara sampai pesawat mendarat kembali di landasan.

\section{PERANCANGAN DAN REALISASI LANDING GEAR SYSTEM}

\subsection{Gambaran Umum Sistem}

Gambaran umum dari landing gear system ini adalah untuk mengontrol gerakan roda pesawat keluar atau masuk ke dalam pesawat. Selain itu, indikasi dari kondisi ketinggian pesawat dan peringatan terjadinya masalah pada aktuator juga dikontrol oleh alat kontrol landing gear system tersebut. Pilot pesawat dapat menggerakkan roda pesawat hanya dengan menggerakkan slider 2 arah, yaitu atas (up) dan bawah (down) untuk menggerakkan roda naik maupun turun. Informasi berupa masalah pada aktuator double acting cylinder juga dapat diberikan kepada pilot dengan tampilan nyala lampu. Untuk ketinggian pesawat yang telah melewati batas minimum terbang juga dapat ditampilkan berupa bunyi alarm dan lampu yang menyala. Semua kondisi tersebut dapat dikontrol oleh suatu alat kontrol yang dikenal dengan nama PLCmikro. 
Prinsip kerja landing gear system secara umum yang biasa digunakan dalam pesawat terbang dibagi menjadi 5 kondisi. Kelima kondisi tersebut yaitu;

1. Pesawat berada di landasan (ground)

2. Pesawat lepas landas (take off)

3. Pesawat berada di udara

4. Pesawat berada di bawah ketinggian minimum

5. Pesawat dalam posisi mendarat (landing)

\subsection{Perancangan dan Realisasi Perangkat Keras (Hardware)}

Spesifikasi landing gear system yang dirancang dan direalisasikan harus mampu melakukan beberapa proses yaitu:

1. Mendorong roda keluar dari pesawat dan menarik masuk roda ke dalam pesawat

2. Mampu memberikan informasi berupa proses aktuator double acting cylinder yang bermasalah dalam bergerak pada saat mendorong atau menarik roda pesawat.

3. Mampu memberi informasi berupa posisi roda yang telah masuk maupun keluar dari pesawat dalam bentuk nyala lampu.

4. Mampu membaca ketinggian pesawat dan memberikan informasi kepada pilot berupa suara alarm dan lampu.

Berdasarkan spesifikasi landing gear system yang diinginkan, maka blok diagram sistem yang dirancang dapat dilihat pada Gambar 2.

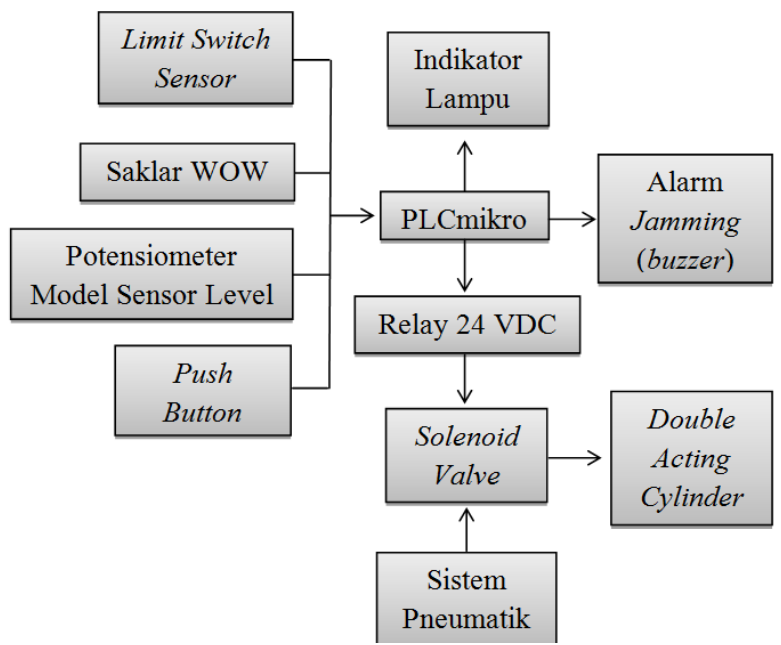

Gambar 2. Blok diagram sistem

Berdasarkan blok diagram pada Gambar 2 dapat dilihat bahwa PLCmikro terdiri dari 4 input dan 3 output. Berikut ini akan dijelaskan mengenai masing-masing fungsi dari input maupun output sistem yang dirancang berdasarkan blok diagram di atas.

1. Limit switch berfungsi untuk mendeteksi aktuator silinder aksi ganda (double acting cylinder) apabila kondisi piston telah bergerak mencapai batas maksimumnya.

2. Saklar WOW digunakan sebagai model dari sensor weight on wheels (WOW). Sensor WOW merupakan sensor yang bekerja seperti saklar yang mengunci sistem menaikkan roda ( gear up) apabila menerima beban.

3. Potensiometer berfungsi sebagai model dari sensor ketinggian.

4. Push button berfungsi sebagai tombol untuk mengaktifkan aktuator solenoid valve agar double acting cylinder dapat menggerakkan roda turun maupun naik ke dalam pesawat terbang. 
5. Indikator lampu pada perancangan kali ini terdiri dari 5 buah lampu LED yang berwarna. Lampu warna kuning sebagai indikasi proses piston double acting cylinder bergerak, putih indikasi roda telah masuk ke dalam pesawat, hijau indikasi roda telah keluar dari dalam pesawat, merah indikasi peringatan posisi pesawat di bawah ketinggian minimum dan biru sebagai indikasi ada masalah pada pergerakan piston yang tidak sempurna.

6. PLCmikro adalah rangkaian elektrik yang dirangkai yang terdiri dari rangkaian sistem minimum PIC16F877A yang berfungsi sebagai control dari landing gear system.

7. Buzzer yang digunakan sebagai informasi kepada pilot sebagai alarm jamming dalam hal ketinggian minimum pesawat.

8. Relay 24 VDC merupakan relay yang digunakan sebagai switch untuk mengaktifkan solenoid valve karena solenoid valve memerlukan input tegangan 24 VDC sedangkan input dari PLCmikro hanya tegangan 5 VDC.

9. Solenoid valve yang digunakan berjenis 4/3 way NC - double electrical control yang berfungsi membuka dan menutup katup (valve) aliran pneumatic ke double acting cylinder.

10. Double acting cylinder merupakan aktuator penggerak roda pesawat. Aktuator ini bergerak dalam dua arah, yaitu arah keluar dan arah masuk ke tabung.

11. Sistem pneumatic merupakan sistem yang penggunaannya memanfaatkan tekanan udara yang dimampatkan. Aliran pneumatic akan masuk ke aktuator sehingga dapat mendorong maupun menarik piston double acting cylinder.

Gambar 3 merupakan realisasi dari keseluruhan perancangan perangkat keras sistem.

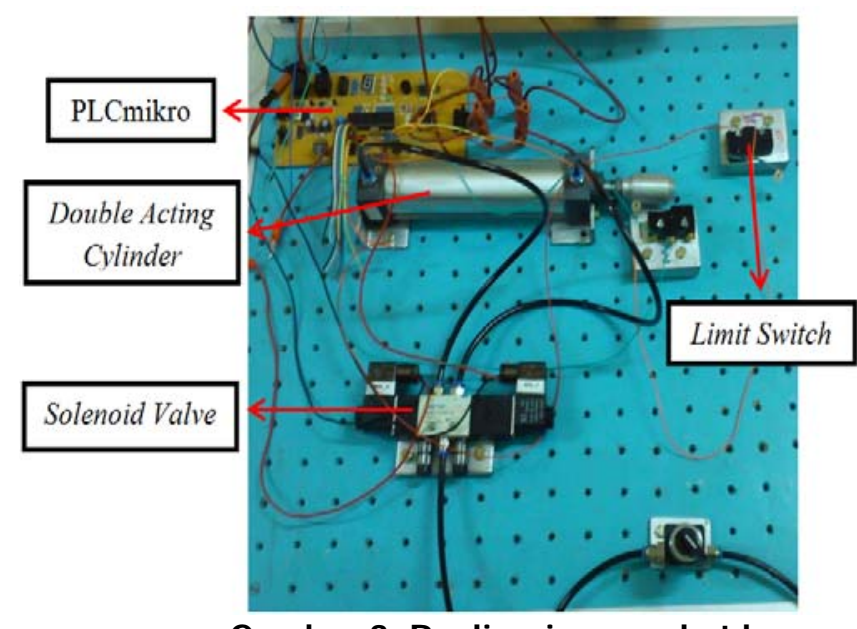

Gambar 3. Realisasi perangkat keras

\subsection{Perancangan dan Realisasi Perangkat Lunak (Software)}

Perancangan perangkat lunak (software) yang dilakukan pada tugas akhir ini meliputi pengaturan kerja mikrokontroller PIC16F877A dalam mengontrol sistem kerja perangkat keras dari landing gear system agar bekerja sesuai dengan spesifikasi sistem yang diinginkan. Adapun perangkat lunak (software) model landing gear system ini mempunyai spesifikasi sebagai berikut :

1. Bahasa pemrograman yang digunakan adalah ladder diagram.

2. Perangkat lunak (software) yang digunakan untuk membuat program pada model landing gear system yaitu Ldmicro. 
3. Menggunakan perangkat lunak (software) PICPgm untuk memasukkan program yang telah di compile ke dalam mikrokontroller PIC16F877A dengan menggunakan kabel serial RS232 dengan sistem ICSP ( / Circuit System Programming).

Gambar 4 menunjukkan flowchart landing gear system yang dirancang untuk diubah ke dalam bentuk bahasa pemrograman ladder diagram.

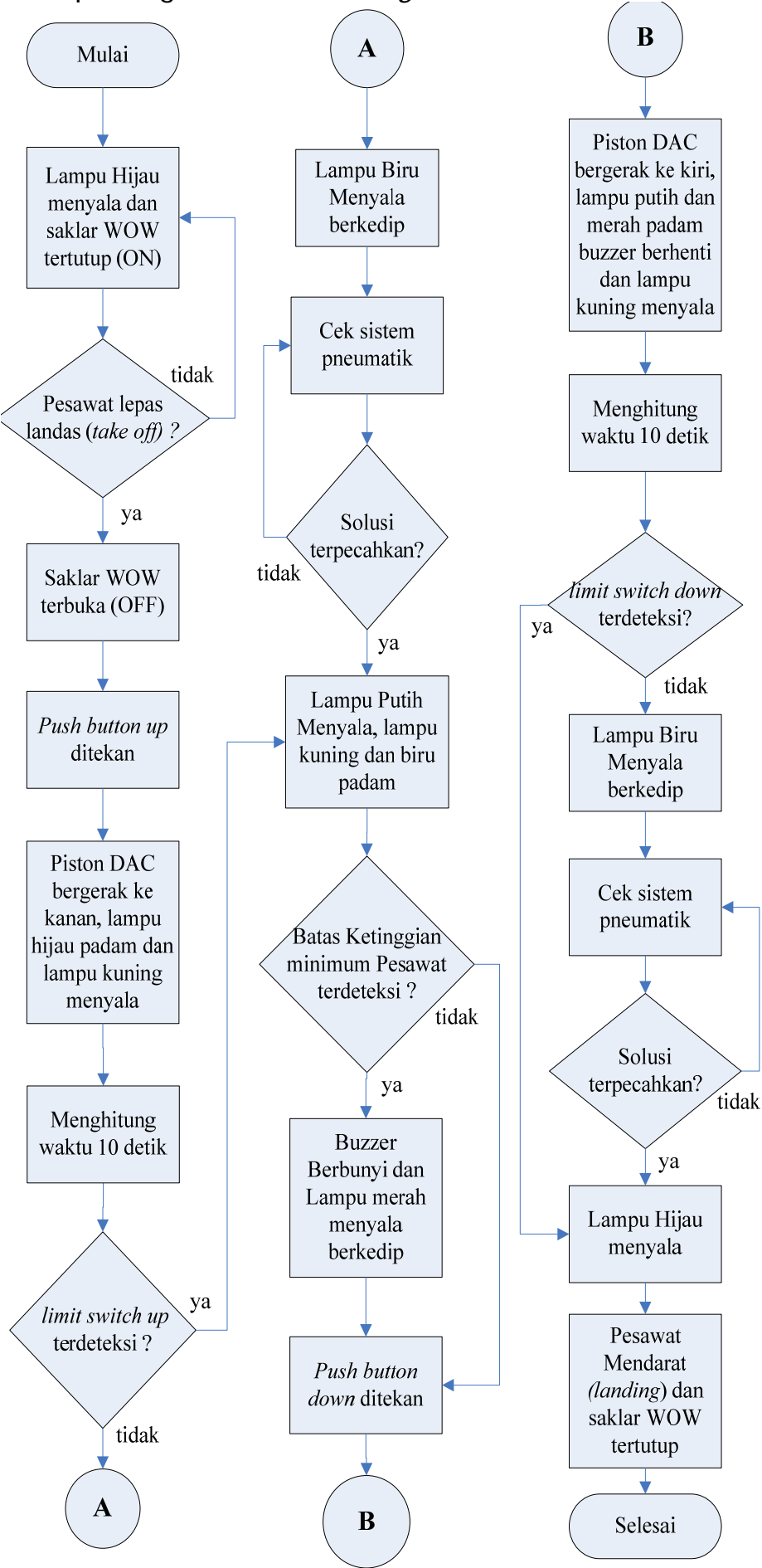

Gambar 4. Flowchart landing gear system 
Berikut ini penjelasan flowchart dari Gambar 4 untuk landing gear system roda pesawat:

1. Sistem dimulai saat pesawat di landasan.

2. Lampu hijau menyala sebagai indikasi roda pesawat berada di bawah (landasan).

3. Saklar sebagai model dari sensor WOW akan aktif (tertutup).

4. Ketika pesawat tinggal landas (take off), saklar sebagai model WOW akan lepas (terbuka).

5. Push button up ditekan sehingga menggerakkan aktuator piston DAC masuk ke dalam pesawat, lampu hijau padam dan lampu kuning menyala.

6. Apabila piston belum menyentuh limit switch up selama lebih dari 10 detik maka lampu peringatan biru menyala berkedip-kedip tetapi lampu kuning tetap menyala. Apabila piston telah menyentuh limit switch up tepat 10 detik atau kurang dari 10 detik maka lampu biru tidak akan menyala, lampu kuning padam dan lampu putih menyala.

7. Jika pesawat terbang pada ketinggian di bawah ketinggian minimum maka alarm buzzer berbunyi, lampu merah menyala berkedip-kedip tetapi lampu putih tetap menyala. Bunyi buzzer berfungsi untuk memberikan indikator kepada pilot agar menaikkan posisi pesawat atau mengeluarkan roda pesawat untuk pendaratan.

8. Jika pilot ingin melakukan pendaratan maka push button down ditekan sehingga menggerakkan aktuator piston DAC keluar dari pesawat, lampu putih dan merah padam, lampu kuning menyala.

9. Apabila piston belum menyentuh limit switch down selama lebih dari 10 detik maka lampu peringatan biru menyala berkedip-kedip tetapi lampu kuning tetap menyala. Apabila piston telah menyentuh limit switch down tepat 10 detik atau kurang dari 10 detik maka lampu biru tidak akan menyala, lampu kuning padam dan lampu hijau menyala.

10. Pesawat landing (mendarat), maka saklar sebagai model WOW akan tertutup (terkunci) dan lampu hijau tetap menyala.

11. Landing gear system selesai.

\section{PENGUJ I AN ALAT}

\subsection{Pengujian Perangkat Keras (Hardware)}

\subsubsection{Pengujian Saklar Sebagai Model Sensor Wheight On Whee/ (WOW)}

Untuk mengetahui mikrokontroller dapat bekerja dengan baik ketika saklar ON adalah dengan cara mengukur tegangan yang masuk ke pin mikrokontroller menggunakan avometer.

Tabel 1. Hasil pengujian saklar sebagai model WOW sensor

\begin{tabular}{ccc}
\hline No. & Kondisi Saklar & Tegangan (volt) \\
\hline 1. & ON & 4,98 \\
\hline 2. & OFF & 0 \\
\hline
\end{tabular}

\subsubsection{Pengujian Solenoid Valve}

Pada pengujian kali ini dilakukan pengukuran tegangan pada input solenoid sehingga dapat diketahui berapa tegangan solenoid yang dibutuhkan untuk mengaktifkan valve pada bagian solenoid valve tersebut. Pengukuran tegangan pada solenoid valve dapat dilakukan menggunakan alat ukur avometer.

Tabel 2 merupakan hasil pengukuran tegangan pada solenoid valve ketika solenoid valve tersebut aktif adalah \pm 24 VDC. 
Tabel 2. Pengukuran tegangan solenoid valve

\begin{tabular}{cccc}
\hline \multirow{2}{*}{ No. Bagian Solenoid Valve } & \multicolumn{2}{c}{ Besar Tegangan (Volt) } \\
\cline { 3 - 4 } & & Aktif & Tidak Aktif \\
\hline 1. & Sol 1 & 24,10 & 0 \\
\hline 2. & Sol_2 & 23,97 & 0 \\
\hline
\end{tabular}

\subsubsection{Pengujian Double Acting Cylinder}

Aktuator selanjutnya yang akan diuji adalah double acting cylinder. Sistem kerja pengujian double acting cylinder dapat dilihat seperti blok diagram pada gambar 5.

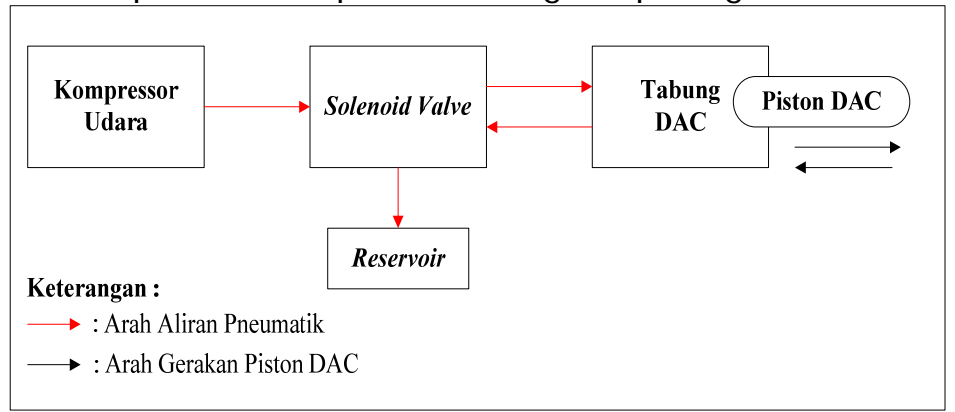

Gambar 5. Blok diagram sistem pengujian pada double acting cylinder

Piston double acting cylinder dapat bergerak apabila mendapat dorongan tekanan pneumatik yang aliranya berasal dari kompressor udara yang dikontrol oleh solenoid valve. Pada pengujian kali ini diinginkan double acting cylinder bergerak ke kanan apabila solenoid valve 1 (sol_1) aktif, dan bergerak ke kiri apabila solenoid valve 2 (sol_2) aktif.

Gambar 6 merupakan actuator double acting cylinder yang bergerak ke kanan setelah sol_1 aktif.

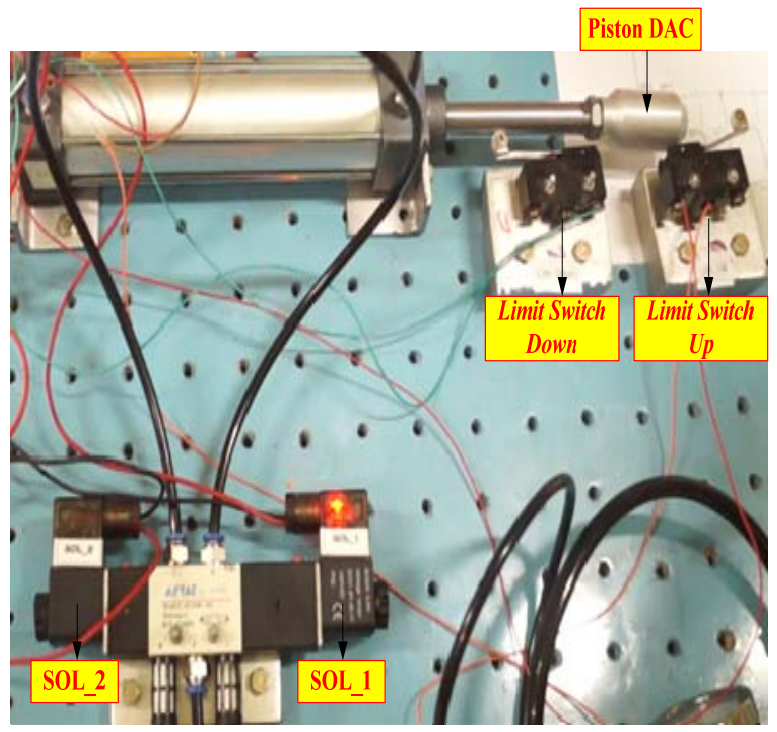

Gambar 6. Double acting cylinder bergerak ke kanan

Untuk hasil pengujian double acting cylinder yang bergerak ke kiri akibat katup (valve) pada sol_2 aktif dapat dilihat pada Gambar 7. 


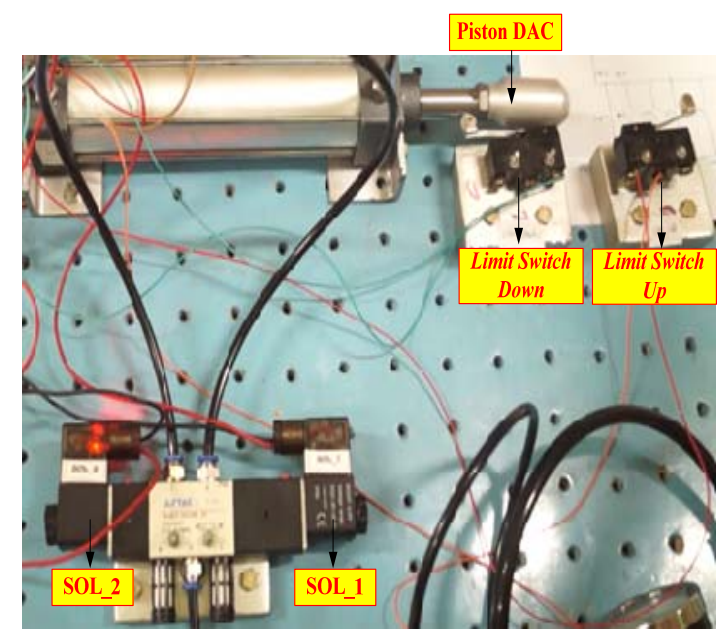

Gambar 7. Double acting cylinder bergerak ke kiri

\subsubsection{Pengujian Limit Switch Sensor}

Pengujian yang dilakukan pada limit switch dengan mengukur tegangan yang masuk ke dalam mikrokontroler ketika switch tertutup (kondisi aktif). Berikut ini gambar limit switch down yang aktif ketika disentuh ujung piston double acting cylinder.

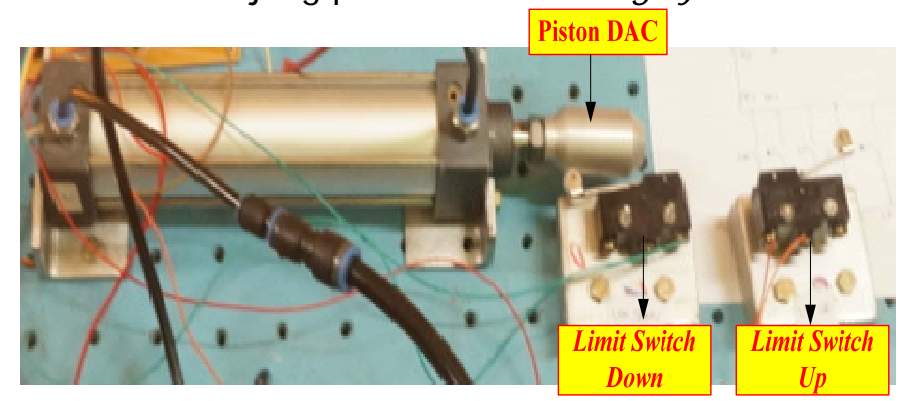

Gambar 8. Kondisi limit switch down aktif

Tabel 3 menunjukkan hasil pengukuran tegangan limit switch menggunakan multimeter ketika limit switch up maupun down dalam keadaan aktif dan tidak aktif.

Tabel 3. Pengukuran tegangan input limit switch

\begin{tabular}{cccc}
\hline \multirow{2}{*}{ No. } & \multirow{2}{*}{ Jenis Limit Switch } & \multicolumn{2}{c}{ Besar Tegangan (volt) } \\
\cline { 3 - 4 } & Lim up & Aktif & Tidak Aktif \\
\hline 1. & Lim_down & 4,01 & 0 \\
\hline 2. & & 4,99 & 0 \\
\hline
\end{tabular}

\subsubsection{Pengujian Lampu LED}

Pada pengujian lampu LED ini ingin dilihat apakah semua LED bekerja dengan baik dan sesuai sistem atau tidak. Umumnya lampu LED akan ON apabila menerima logic 1 pada pin inputnya. Sedangkan akan OFF jika menerima logic 0. Dalam rangkaian PLCmikro ini, lampu LED yang digunakan ada 5 buah dengan berbagai macam warna.

Tabel 4 menunjukkan pengukuran tegangan lampu LED beserta keterangannya. 
Tabel 4. Pengukuran tegangan lampu LED

\begin{tabular}{ccccc}
\hline \multirow{2}{*}{ No. } & Warna Lampu LED & \multicolumn{2}{c}{$\begin{array}{c}\text { Pengukuran Tegangan } \\
\text { (volt) }\end{array}$} & \multirow{2}{*}{ Keterangan } \\
\cline { 3 - 4 } & & Aktif & Tidak Aktif & \\
\hline 1. & Hijau & 2,97 & 0 & limit down aktif \\
\hline 2. & Putih & 2,99 & 0 & limit up aktif \\
\hline 3. & Kuning & 2,94 & 0 & proses DAC \\
\hline 4. & Merah & 2,97 & 0 & warning level \\
\hline 5. & Biru & 2,99 & 0 & masalah pada DAC \\
\hline
\end{tabular}

\subsection{Pengujian Perangkat Lunak (Software)}

Pengujian perangkat lunak (software) menggunakan software automotion studio 5.0 . Software automotion studio 5.0 merupakan simulator dalam bentuk electrical pneumatichidraulic system. Gambar 9 menunjukkan simulasi menggunakan Automotion Studio 5.0 pada kondisi pesawat di landasan.

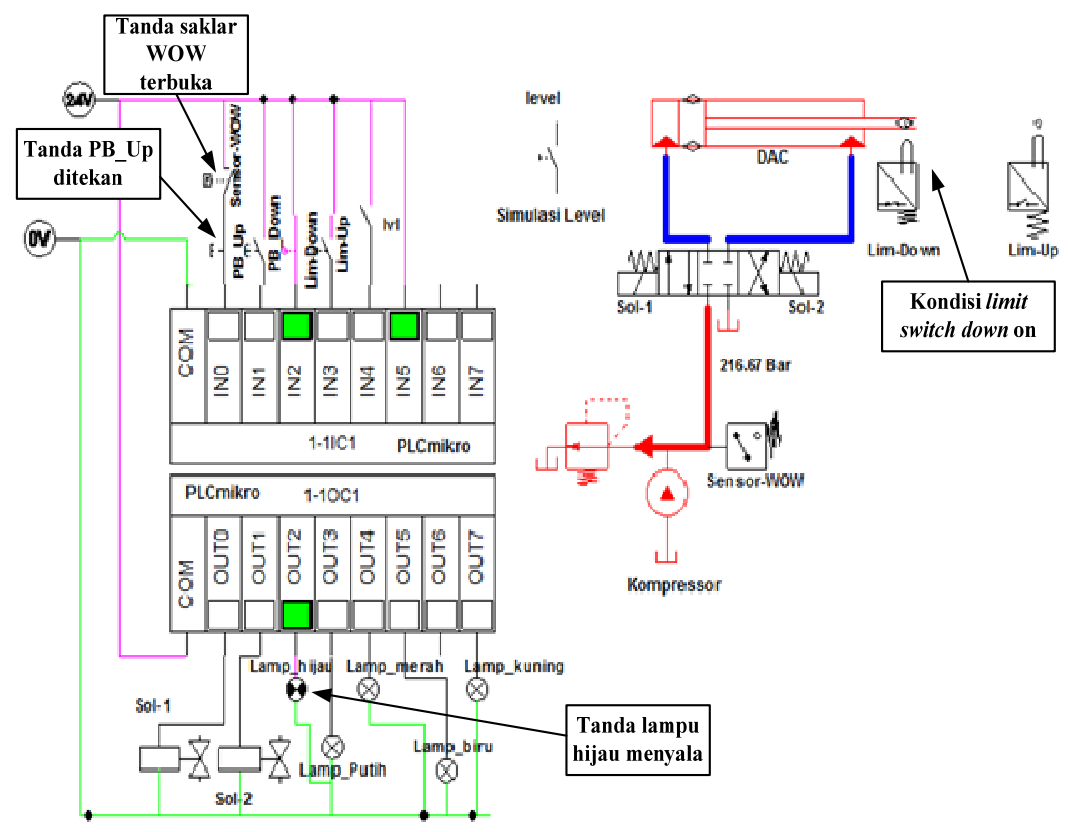

Gambar 9. Hasil simulasi automotion studio 5.0 pada kondisi di landasan

Berdasarkan hasil pengujian sistem secara simulasi dapat dilihat bahwa ketika di landasan, saklar WOW akan aktif sehingga kontak bagian yang terhubung ke PB_Up akan terputus. Akibatnya ketika PB_Up ditekan, tidak akan melakukan aksi apapun pada aktuator. Hal ini sebagai bentuk sistem keamanan yang dibuat saat pesawat berada di landasan.

\subsection{Pengujian Sistem Secara Keseluruhan}

Setelah mengintegrasikan keseluruhan sistem, perangkat keras dan perangkat lunak, maka dilakukan pengujian terhadap sistem secara keseluruhan. Tujuan melakukan pengujian tersebut untuk melihat kinerja sistem yang dirancang secara perangkat keras ( hardware) dan perangkat lunak (software) agar dapat bekerja dengan baik sesuai yang diinginkan. 
Pengujian landing gear system secara keseluruhan yang beroperasi tiap kondisi, mulai dari kondisi pesawat berada di landasan, pesawat lepas landas (take off), pesawat berada di udara, pesawat mengalami masalah pada gerakkan piston double acting cylinder, pesawat berada di ketinggian minimum dan pesawat mendarat ( /anding).

Tabel 5. Hasil pengujian sistem secara keseluruhan

\begin{tabular}{|c|c|c|c|c|c|c|c|c|}
\hline \multirow{3}{*}{ Bagian } & \multirow{3}{*}{ Nama Komponen } & \multicolumn{7}{|c|}{ Kondisi pesawat } \\
\hline & & \multirow[t]{2}{*}{ Landasan } & \multirow{2}{*}{$\begin{array}{c}\text { Lepas } \\
\text { landas } \\
\text { (take off) }\end{array}$} & \multicolumn{2}{|c|}{$\begin{array}{c}\text { Piston DAC } \\
\text { bergerak } \\
\text { (>10 detik) }\end{array}$} & \multirow[t]{2}{*}{ di udara } & \multirow{2}{*}{$\begin{array}{c}\text { Ketinggian } \\
\text { minimum }\end{array}$} & \multirow{2}{*}{$\begin{array}{l}\text { Mendarat } \\
\text { ( landing) }\end{array}$} \\
\hline & & & & Up & Down & & & \\
\hline \multirow{6}{*}{ Input } & PB_Up & $x$ & $\checkmark$ & $\checkmark$ & $x$ & $x$ & $x$ & $x$ \\
\hline & PB_Down & $x$ & $\mathrm{x}$ & $x$ & $\checkmark$ & $x$ & $\mathrm{x}$ & $\checkmark$ \\
\hline & Lim_Up & $x$ & $x$ & $x$ & $x$ & $\checkmark$ & $\checkmark$ & $x$ \\
\hline & Lim_Down & $\checkmark$ & $x$ & $x$ & $x$ & $x$ & $x$ & $x$ \\
\hline & Saklar WOW & $\checkmark$ & $x$ & $x$ & $x$ & $x$ & $x$ & $x$ \\
\hline & Sensor level & $x$ & $x$ & $x$ & $x$ & $x$ & $\checkmark$ & $x$ \\
\hline \multirow{8}{*}{ Output } & Lamp_hijau & $\checkmark$ & $x$ & $x$ & $x$ & $x$ & $x$ & $x$ \\
\hline & Lamp_kuning & $x$ & $\checkmark$ & $\checkmark$ & $\checkmark$ & $x$ & $x$ & $\checkmark$ \\
\hline & Lamp_putih & $x$ & $x$ & $x$ & $x$ & $\checkmark$ & $\checkmark$ & $x$ \\
\hline & Lamp_biru & $x$ & $x$ & $\checkmark$ & $\checkmark$ & $x$ & $x$ & $x$ \\
\hline & Lamp_merah & $x$ & $x$ & $x$ & $x$ & $x$ & $\checkmark$ & $x$ \\
\hline & Buzzer & $x$ & $x$ & $x$ & $x$ & $x$ & $\checkmark$ & $x$ \\
\hline & Solenoid valve & $x$ & $\checkmark$ & $\checkmark$ & $\checkmark$ & $x$ & $x$ & $\checkmark$ \\
\hline & $\begin{array}{c}\text { Double Acting } \\
\text { Cylinder }\end{array}$ & $x$ & $\checkmark$ & $\checkmark$ & $\checkmark$ & $x$ & $x$ & $\checkmark$ \\
\hline
\end{tabular}

Keterangan :

$$
\begin{array}{ll}
\checkmark & : \text { Kondisi AKTIF } \\
\mathrm{x} & : \text { Kondisi TIDAK AKTIF }
\end{array}
$$

Berdasarkan hasil pengujian pada Tabel 5 dapat dilihat bahwa kondisi pesawat ketika di landasan, lepas landas hingga mendarat kembali sudah sesuai dengan spesifikasi sistem yang diinginkan. Salah satu contohnya pada spesifikasi tersebut diinginkan sistem harus mampu mendorong roda keluar dari pesawat atau masuk ke pesawat. Realisasinya dapat dilihat pada tabel 5 bagian kondisi lepas landas. Ketika lepas landas input yang bekerja yaitu push button up untuk mengaktifkan solenoid valve sehingga piston double acting cylinder dapat bergerak ke kanan.

\section{KESI MPULAN}

Berdasarkan hasil perancangan, realisasi dan pengujian terhadap kontrol landing gear system menggunakan PLCmikro berbasis PIC16F877A yang telah dilakukan, maka dapat diambil beberapa kesimpulan sebagai berikut :

1. Tegangan \pm 24 VDC pada salah satu bagian solenoid (sol_1 atau sol_2) dapat menggerakkan katup (valve) sehingga aliran pneumatik dapat diteruskan ke aktuator double acting cylinder berupa gerakkan piston masuk maupun keluar tabung. 
2. hasil pengujian sistem double acting cylinder telah sesuai dengan sistem yg diinginkan. Sol_1 menggerakkan piston double acting cylinder keluar tabung, sedangkan sol_2 menggerakkan piston double acting cylinder masuk ke tabung.

3. Data hasil pengujian lampu LED sebagai indikator sistem yang terdiri dari 5 warna, yaitu hijau, putih, kuning, biru dan merah dapat aktif dan bekerja sesuai sistem yang diinginkan. Hijau merupakan indikator limit switch down aktif, putih indicator limit switch up aktif, kuning merupakan proses pergerakkan piston double acting cylinder, biru sebagai indikator ada masalah pada pergerakkan piston dan merah indikator peringatan ketinggian pesawat di bawah ketinggian minimum terbang.

4. Integrasi antara perangkat keras (hardware) dan lunak (software) telah bekerja sesuai spesifikasi sistem yang diinginkan.

\section{DAFTAR RUJ UKAN}

Artanto, Dian. (2012). 60-Aplikasi PLCmikro. Jakarta: Elexmedia Komputindo.

Albayumi, Usep. (2012). Pelatihan PLC Dasar Diklat PT Dirgantara Indonesia. Bandung: PT Dirgantara Indonesia.

Said, Hanif. (2013). Aplikasi Programmable Logic Controller (PLC) dan Sistem Pneumatik pada Industri. J akarta: Andi Publisher.

Donny, W. P. (2012). Rancang Bangun Prototipe Robot Pengangkut Pallet dengan Teknik Kontrol Wireless Berbasis PLCmikro. Bandung: Politeknik TEDC.

Eka, P. H. (1983). Rancangan Aktuator Pada Roda Pendarat Depan Pesawat N-228. Bandung: PT Dirgantara Indonesia.

Bambang, Emil. (1991). Perencanaan Awal Roda Pendarat Sistem Twin Wheel Pada Pesawat CN-235. Bandung: PT Dirgantara Indonesia. 